\title{
Pemberdayaan Masyarakat di Sekitar Cagar Budaya Melalui Pameran Museum
}

\author{
Sektiadi, Djaliati Sri Nugrahani \\ Departemen Arkeologi, Fakultas Ilmu Budaya, Universitas Gadjah Mada
}

\begin{abstract}
Abstrak
Salah satu upaya pemanfaatan menjadikan cagar budaya adalah menjadikanny asebagai sumber inspirasi. Dalam hal ini, cagar budaya Candi Sojiwan digunakan sebagai bahan inspirasi untuk pengembangan masyarakat di sekitarnya. Masyarakat didorong untuk mengambil manfaat dari keberadaan candi, yaitu dengan menggunakannya sebagai sumber inspirasi desain motif kain yang kemudian dikembangkan menjadi kerajinan batik. Langkah berikutnya, perajin perlu dipaparkan langsung kepada publik batik, baik desainer, produsen, maupun konsumen. Untuk itu, perlu dilakukan pameran dengan keperluan agar batik yang dihasilkan mendapat apresiasi dari khalayak lebih luas.

Pameran batik dilakukan dengan model pameran museum, yang memiliki spesifikasi terutama dalam penyampaian cerita, atau objek sebagai bagian dari menampilkan gagasan. Pameran dilakukan di Museum UGM untuk menjangkau kalangan yang selama ini tidak bersentuhan langsung dengan para perajin, yaitu komunitas batik dan akademisi.
\end{abstract}

Kata kunci: pengabdian, candi, museum, pameran, batik

\begin{abstract}
One of the efforts to utilize the cultural heritage is to make it as a source of inspiration. In this case, the cultural heritage of Sojiwan Temple is used as an inspiration for the development of surrounding communities. People are encouraged to take advantage of the existence of the temple, namely by using it as a source of design inspiration cloth motif which later developed into batik craft. The next step, crafters need to be presented directly to the batik community, both designers, manufacturers, and consumers. Therefore, it is necessary to do the exhibition with the need for the resulting batik gets appreciation from the wider audience. Batik exhibition is done by museum exhibition model, which has specification especially in delivery of story, or object as part of showing ideas. The exhibition was held at the UGM Museum to reach out to people who have not been in direct contact with the craftsmen, the batik community and academics.
\end{abstract}

Keywords: community engagement, temple, museum, exhibition, batik

\section{Pendahuluan}

Pelestarian cagar budaya memiliki pengertian baru di Indonesia dengan ditetapkannya undang-undang Cagar Budaya nomor 11 tahun 2010. Dalam undang-undang tersebut ditetapkan bahwa pelestarian meliputi tiga tindakan, yaitu pelindungan, pemanfaatan, dan pengembangan. Di samping itu, pelestarian cagar budaya juga bergeser dari orientasi kepada pemerintah menjadi pengembangan manfaat bagi masyarakat.

Dalam kerangka pemikiran tersebut, kegiatan pelestarian mestinya memperhatikan masyarakat yang tinggal di sekitar cagar budaya. Mereka adalah orang-orang yang 
secara langsung bersinggungan dengan cagar budaya dalam keseharian. Oleh karena itu, merekalah yang mestinya pertama-tama mendapat manfaat.

Selama ini, manfaat secara ekonomi masih mendominasi pemikiran tentang cagar budaya dan juga warisan budaya secara umum. Ekonomi sering dianggap sebagai mendapatkan keuntungan finansial secara langsung, seperti menarik tiket dari para wisatawan yang berkunjung dan upaya kontraproduktif berupa penjualan warisan budaya. Pemikiran tentang pemanfaatan nilai ekonomi dalam industri kreatif cukup jarang terdapat meski di sana-sini upaya ke arah hal tersebut telah muncul (Hampton, 2005).

Salah satu upaya pemanfaatan yang dapat dilakukan adalah menjadikan cagar budaya sebagai sumber inspirasi. Dalam hal ini, cagar budaya Candi Sojiwan digunakan sebagai bahan inspirasi untuk pengembangan masyarakat di sekitarnya. Masyarakat didorong untuk mengambil manfaat dari keberadaan candi, yaitu dengan menggunakannya sebagai sumber inspirasi desain motif kain yang kemudian dikembangkan menjadi kerajinan batik.

Namun, pembuatan kain batik dengan desain yang mengambil inspirasi dari cagar budaya perlu perjalanan yang panjang agar dapat matang dan mendatangkan manfaat yang optimal. Perajin perlu dikenalkan langsung kepada publik batik, baik desainer, produsen, maupun konsumen. Untuk itu, perlu dilakukan pameran dengan keperluan agar batik yang dihasilkan mendapat apresiasi dari khalayak lebih luas.

Di luar upaya pelestarian tersebut, terdapat masalah pemberdayaan masyarakat. Upaya ini sering diterjemahkan dengan membantu masyarakat untuk dapat melakukan sesuatu yang bermanfaat bagi mereka. Kegiatan yang banyak dilakukan adalah memberikan pendampingan berupa penyuluhan, pelatihan, serta bantuan material. Cukup jarang dilakukan pendampingan yang berupaya membuat masyarakat mandiri.

Kelompok pembatik Sojiwan berdiri sejak tahun 2013, di Desa Kebondalem Kidul, Kecamatan Prambanan, Klaten. Di sebelah selatan pedukuhan tersebut terdapat peninggalan arkeologis berupa Candi Sojiwan, dari sekitar abad ke-10 Masehi. Candi dari agama Budha ini sangat menarik karena mengandung cerita binatang (fabel) dari genre Tantri pada dinding batur (Gutomo, n.d.). Cerita Tantri mengandung ajaranajaran moral universal yang masih relevan dengan kondisi zaman sekarang bagi semua umat manusia.

Pendirian kelompok tersebut didampingi oleh UNESCO Kantor Jakarta. Pendampingan yang dilakukan bersifat penguatan kelembagaan dan bantuan permodalan. Kegiatan pendampingan tersebut tetap berlanjut hingga kini. Salah satu bentuknya adalah memberikan bantuan desain batik dengan model yang diambil dari relief candi. Pola tersebut kemudian digunakan oleh kelompok untuk mengembangan kerajinan batik mereka. ${ }^{1}$

Pada tahun 2015, Balai Pelestarian Cagar Budaya melakukan pendampingan terhadap kelompok tersebut berupa pelatihan keterampilan membatik. Dalam kegiatan tersebut, separuh anggota kelompok pembatik diberi pelatihan berbagai hal berkait dengan batik di Balai Besar Kerajinan dan Batik Yogyakarta. Mereka kemudian menularkan keterampilan kepada anggota kelompok lain. ${ }^{2}$

Pada akhir tahun 2015, Jurusan Arkeologi FIB UGM memberikan penguatan

1 Observasi lapangan, November 2015.

2 Wawancara dengan Deny Wahyu Hidayat, staf BPCB Jawa Tengah, November 2015. 
dengan melatih para pembatik agar dapat melakukan proses desain batik secara mandiri. Selama ini, mereka tergantung kepada pihak luar dalam hal desain batik. Pada tahun 2016, Departemen Arkeologi (d.h. Jurusan Arkeologi) kembali melakukan pendampingan, dengan upaya penyegaran desain yang telah terasa menjenuhkan, dan mendorong agar mereka memiliki kekhasan batik untuk dapat bersaing dengan perajin batik dari wilayah lain (Tim Jurusan Arkeologi FIB UGM, 2015). Pada tahun berikutnya, melalui serangkaian diskusi dengan fasilitator dari Departemen Arkeologi, kelompok kegiatan tersebut memutuskan untuk mengambil tema tantri, yaitu fabel atau cerita binatang yang terukir pada bagian batur Candi Sojiwan, sebagai ciri khas batik yang mereka kembangkan. ${ }^{3}$

Untuk lebih mematangkan perkembangan, maka diperlukan upaya untuk mempertemukan kelompok tersebut dengan komunitas batik dan akademisi agar dapat berdialog dan pada gilirannya akan mematangkan proses batik mereka. Untuk itu digagas pameran yang diadakan di luar kebiasaan mereka, yaitu di kampus. Dengan demikian mereka akan lebih terhubung dengan publik yang lebih luas dan kritis.

\section{Kegiatan Pameran}

Pameran batik dari kelompok batik "Sojiwan" dilakukan dengan model pameran museum, yang memiliki spesifikasi terutama dalam penyampaian cerita, atau objek sebagai bagian dari menampilkan gagasan. Pameran dilakukan di Museum UGM untuk menjangkau kalangan yang selama ini tidak bersentuhan langsung dengan para perajin, yaitu komunitas batik dan akademisi. Selama ini, kelompok batik ini lebih berhubungan dengan publik secara komersial, yaitu dengan mengikuti 'pameran' atau event tertentu dengan tujuan menjual batik yang mereka hasilkan.

Pameran museum berbeda dari pameran komersial. Pameran yang disebut terakhir memiliki tujuan untuk menjual produk atau jasa untuk mendapatkan keuntungan finansial, sementara pameran museum dalam kategori public service exhibit, memberitahu khalayak serta mengubah sikap dan kebiasaan (Dean, 1998, hal. 2). Lebih khusus lagi, karena museum merupakan tempat untuk pengkajian, belajar, dan refleksi, maka pameran museum merupakan kegiatan yang bersifat edukatif.

Efek lanjutan yang dicapai dengan kegiatan ini adalah memperkenalkan kepada publik tentang manfaat dari cagar budaya. Hasil budaya ini tidak hanya merupakan benda yang diberi pelindungan, tetapi juga pengembangan dan pemanfaatan, yang ketiganya masuk ke dalam kategori pelestarian menurut Undang-Undang nomor 11 tahun 2010 tentang Cagar Budaya (UUCB, 2010). Diharapkan, selain batik Sojiwan terangkat, juga memberi inspirasi kepada kalangan batik dan akademisi untuk lebih melestarikan cagar budaya, setidaknya melalui pemanfaatan.

Luaran (outcome) utama yang diperoleh adalah terselenggaranya kegiatan pameran. Pameran ini telah diselenggarakan di Museum UGM, pada tanggal 28 November hingga 10 Desember 2016. Sementara itu, luaran sampingan adalah artikel publikasi, serta poster publikasi.

Untuk dapat memenuhi tujuannya, yaitu edukasi, kegiatan pameran museum dilakukan melalui beberapa tahap atau fase. Dean (1998, hlm. 9) menjelaskan tahap-

3 Catatan Lapangan. 
tahap tersebut adalah: 1) tahap konseptual, 2) tahap pengembangan, 3) tahap fungsional, dan 4) tahap asesmen. Lebih rinci, pada tahap konseptual terdapat pengumpulan gagasan untuk pameran. Pada tahap pengembangan dibuatlah a) perencanaan dan b) produksi pameran. Pada tahap fungsional terdapat sub-tahap a) operasional dan b) pembongkaran (terminating), sementara tahap terakhir, yaitu asesmen, terdapat sub bagian a) evaluasi dan b) pengumpulan gagasan.

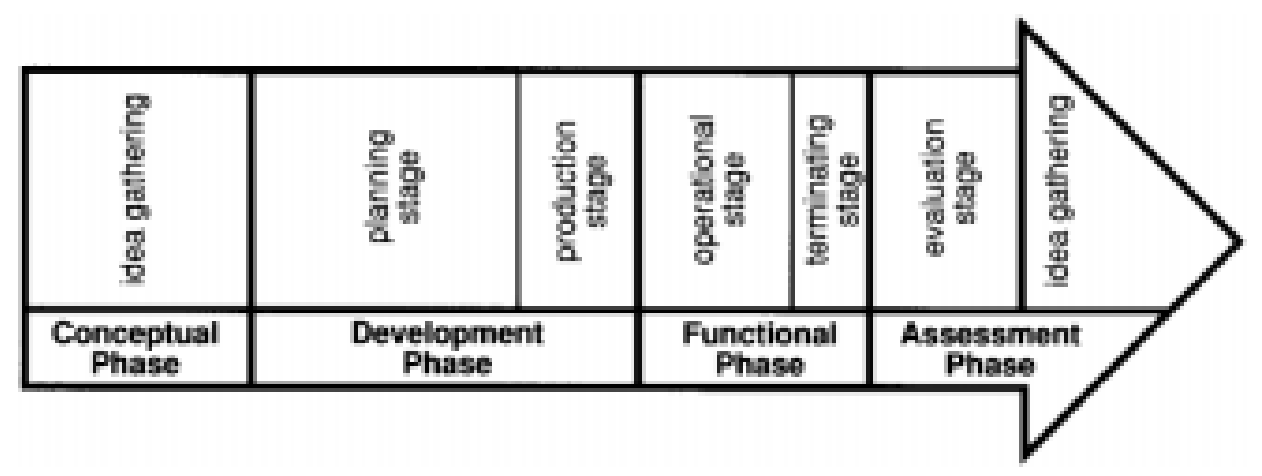

Diagram 1. Model Proses Pameran. Sumber: Dean 1998: 9.

Pada tahap konseptual, dilakukan brainstorming dengan anggota tim, mengenai pameran yang akan dilakukan, terutama topik dan hal-hal teknis seperti waktu dan tempat. Pada tahap ini dihasilkan keputusan untuk memamerkan perjalanan rancangan batik, dari konsep hingga eksekusi yang dilakukan oleh kelompok batik "Sojiwan”, juga proses yang melatarinya. Dengan demikian akan diperoleh gambaran yang menyeluruh tentang proses, kegiatan, serta produk batik lengkap dengan aspek yang lebih bersifat filosofis seperti semangat.

Pada tahap pengembangan, dilakukan perencanaan yang lebih matang, menghubungi para stakeholder, serta melakukan instalasi pameran. Perencanaan dilakukan termasuk merancang alur cerita (story line) yang merupakan ciri khas dari pameran museum.

Pada tahap ini juga dilakukan pengumpulan dan pemilihan objek, serta pembuatan pameran. Pengumpulan objek yang digunakan untuk pameran dilakukan dengan melihat alur cerita dan menghubungi pihak-pihak yang memiliki objek yang dimaksud. Beberapa objek harus dihadirkan dan menjadi properti pameran. Hal lain dari materi pameran yang harus ada ialah label dan poster yang berisi teks tentang pameran, tentang objek, dan bahan-bahan pendukung seperti foto dan gambar desain.

Pembuatan/penataan pameran dilakukan dengan memasukkan berbagai perlengkapan ke ruang pamer sesuai dengan alur cerita dan denah blok pameran. Beberapa perlengkapan antara lain adalah partisi dan vitrin, lampu, serta perlengkapan audio-visual. Pada tahap ini juga telah dibuat rancangan publikasi sekaligus memulai pelaksanaannya baik melalui poster maupun media sosial. Selain itu, dirancang acara yang akan berlangsung pada tahap berikutnya. Acara tersebut meliputi pembukaan dan workshop.

Pada tahap ketiga, yaitu tahap fungsional, dilakukan operasional pameran. Kegiatan tersebut dimulai dari pembukaan pameran, yang dilakukan oleh Wakil Dekan Bidang Keuangan, Aset, dan Sumberdaya Manusia Fakultas Ilmu Budaya Universitas Gadjah 
Mada, yaitu Drs. Heru Marwata, M.Hum. Undangan dalam acara ini adalah para anggota kelompok batik "Sojiwan", wakil instansi terkait (BPCB Jawa Tengah dan BPCB DIY, Bappeda Kab. Klaten, Kepala Desa Kebondalem Kidul), serta para dosen dan mahasiswa di Departemen Arkeologi FIB UGM.

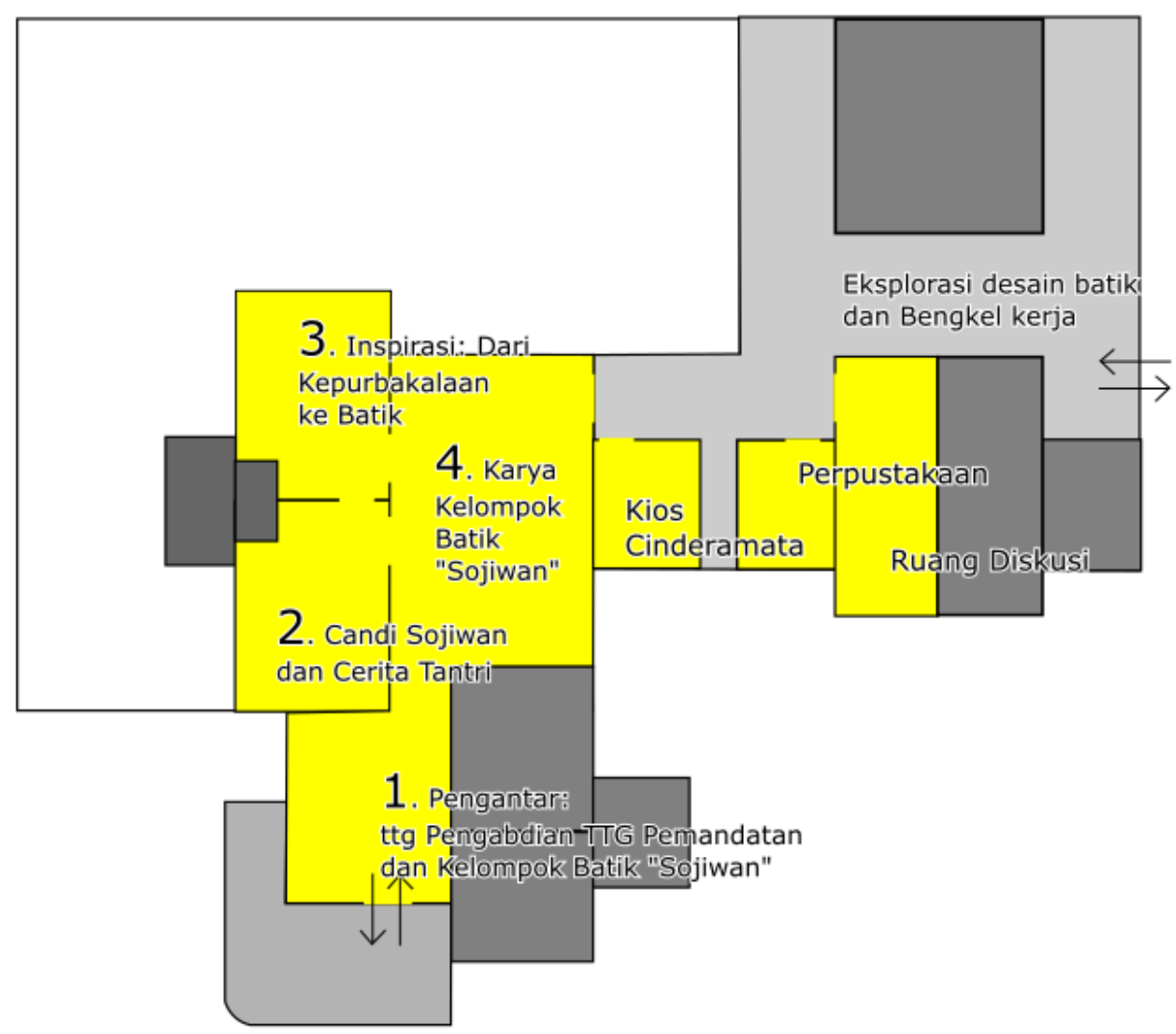

Diagram 2. Alur cerita dan denah blok ruang pamer di Museum UGM.

Workshop yang diselenggarakan adalah kelas batik, melibatkan 30-an peserta dalam dua kali kegiatan. Sebagai instruktur adalah para pembatik dari Kelompok Batik "Sojiwan". Peserta membuat kain batik, mulai dari menggambar pada kain dengan pensil, mencanting, mewarnai, hingga me-lorod.

Tahap pembongkaran dilakukan setelah penutupan, dengan mengemasi objek dan segenap perlengkapan yang dipasang di ruang pamer. Pada tahap ini juga dilakukan pengembalian semua benda yang merupakan pinjaman, dan menyimpan perlengkapan yang dapat digunakan lagi untuk kegiatan berikutnya.

Tahap terakhir, yaitu asesmen, dilakukan dengan membuat evaluasi atas keseluruhan kegiatan. Berbagai temuan didiskusikan dan didokumentasi untuk penyempurnaan kegiatan berikutnya. Gagasan-gagasan baru juga muncul untuk kegiatan lain.

\section{Pembahasan}

Beberapa hasil yang dicapai antara lain adalah terlaksananya pameran, diseminasi gagasan, munculnya kontak baru, dan dialog dengan stakeholder. 


\section{Pameran terlaksana}

Pameran dilaksanakan di Museum UGM, pada tanggal 28 November hingga 10 Desember 2016. Pada pameran juga dilakukan acara/upacara pembukaan dan workshop. Selain sebagai peresmian pameran, pembukaan juga dilakukan untuk memberitahu kepada berbagai pihak, tentang adanya acara pameran tersebut, dan juga memberitahukan keberadaan kelompok batik "Sojiwan".

\section{Kontak-kontak baru}

Pameran yang dilakukan di luar kebiasaan Kelompok Batik "Sojiwan” mendatangkan kontak baru, setidaknya mereka yang mengunjungi pameran di Museum UGM tersebut. Daftar pengunjung ini dapat dibaca pada buku tamu pengunjung. Kelompok binaan juga menyebarkan kartu nama pada pengunjung sehingga kontak di luar pameran diharapkan dapat terjadi.

\section{Diseminasi gagasan}

Pertemuan dengan berbagai pihak, terutama pemerhati kriya batik dan kalangan peminat arkeologi publik (setidaknya adalah mahasiswa dan dosen Arkeologi), memberikan pengetahuan kepada khalayak yang lebih luas tentang kemungkinan-kemungkinan yang terjadi pada pertemuan antara cagar budaya, khususnya bangunan candi, dengan kriya batik.

Diseminasi ini semakin meluas dengan adanya liputan media massa, antara lain Harian Kedaulatan Rakyat, dan RCTI lokal Yogyakarta. Khalayak yang tidak mengunjungi pameran pun dapat mengetahui adanya gagasan 'baru' untuk mengangkat tema candi ke dalam desain batik, atau sebaliknya, memperluas cakrawala desain batik dengan menggali gagasan-gagasan ornamental yang pernah ada di lingkungan setempat.

\section{Penilaian stakeholder}

Sebagian pengunjung tidak hanya menikmati pameran, mengambil manfaat seperti informasi atau membuat gagasan baru bagi mereka sendiri, namun terdapat beberapa pengunjung yang menyampaikan penilaian atas batik yang dihasilkan oleh kelompok binaan. Penilaian ini dilakukan dengan berbagai cara, antara lain dikemukakan secara langsung (kepada pemandu, panitia, juga kepada anggota kelompok yang kebetulan hadir), atau melalui catatan pada buku kesan.

Salah satu penilaian datang dari pengusaha batik yang memiliki toko yang cukup terkenal di Yogyakarta. Pengunjung ini menyatakan bahwa para perajin di kelompok batik binaan tersebut sudah membuat dengan baik, beberapa bernilai "komersial' yang cukup. Namun, perlu penambahan "jam terbang" atau pengalaman agar motif yang dihasilkan cukup luwes.

\section{Gagasan baru}

Gagasan muncul di sisi penyelenggaraan pameran dan di sisi pembinaan desain batik. Dari sisi penyelenggaraan, gagasan terutama berupa perbaikan seperti persiapan yang lebih panjang agar semua hal yang disajikan dalam pameran cukup matang, juga penambahan acara seperti workshop yang tidak hanya terjadwal (dua kali selama pameran), namun juga workshop kecil yang dapat dilakukan setiap saat oleh pengunjung. 
Workshop ini misalnya adalah membuat desain dengan pensil, kertas, dan mal plastik yang dapat dicetak dengan mudah. Jangkauan khalayak juga semestinya diperluas dengan mengundang berbagai komunitas batik secara langsung. Pameran juga sebaiknya dilakukan secara berkala untuk menjaga semangat para pembatik untuk terus berinovasi dalam hal motif batik.

Dari sisi pembinaan, terlihat bahwa para perajin memerlukan acuan yang banyak untuk mereka kembangkan sebagai desain. Dari hasil pembinaan selama satu tahun, ternyata tidak banyak desain yang mereka kembangkan sendiri.

\section{Kesimpulan dan Saran}

\section{Kesimpulan}

Pengabdian kepada masyarakat dengan cara memamerkan hasil pekerjaan mereka dapat memberikan nilai tambah bagi berbagai pihak. Bagi masyarakat sendiri, produk yang mereka hasilkan dapat lebih dikenal di luar publik yang selama ini menjadi jangkauan kegiatan mereka, dan mendapat masukan dari sisi desain. Bagi kalangan batik, terdapat inspirasi baru untuk mengembangkan batik dari sisi desain, yaitu dengan mengambil ragam hias pada candi atau cagar budaya lain. Bagi kalangan akademisi, menjadi lebih terlihat kemungkinan untuk kegiatan arkeologi publik untuk lebih mendekatkan arkeologi (cagar budaya) dengan masyarakat.

\section{Saran}

Beberapa saran berikut muncul setelah menyelenggarakan pameran museum untuk "batik Sojiwan". Saran pertama adalah agar pihak terkait lebih memperhatikan kelompok-kelompok masyarakat di sekitar cagar budaya. Pihak-pihak ini terutama adalah pemerintah daerah yang selama ini juga berharap pada pengembangan dan pemanfaatan cagar budaya namun lebih terfokus pada wisata langsung ke objek.

Saran berikutnya adalah agar museum juga berbenah diri berguna bagi masyarakat. Museum dapat menyelenggarakan pameran untuk menjembatani para stakeholder museum, yaitu kelompok-kelompok yang ada di masyarakat, instansi-instansi pemerintah, dan pihak akademisi. Mempertemukan mereka di museum (dalam pameran) akan membawa keuntungan baik bagi museum (karena dikunjungi dan kredibiitasnya naik) maupun bagi masyarakat secara luas.

Agar pihak terkait dapat memaknai cagar budaya secara lebih luas, tidak hanya ekonomi-langsung, seperti penjualan tiket wisata ("bisnis portal”), atau bahkan secara sembunyi-sembunyi menjual cagar budaya seperti dilakukan oleh masyarakat di beberapa situs/kawasan cagar budaya.

\section{Daftar Pustaka}

Dean, J. (1998). Museum Exhibition: Theory and Practice. London \& New York: Routledge. Gutomo (Ed.). (n.d.). Kebijaksanaan dari Sojiwan. Klaten: Balai Pelestarian Cagar Budaya Jawa Tengah.

Hampton, M. P. (2005). Heritage, Local Communities and Economic Development. Annals of Tourism Research, 32(3), 735-759. 
64 | Bakti Budaya Vol. 1 No. 1 April 2018

Tim Jurusan Arkeologi FIB UGM. (2015). Laporan Pelaksanaan Pengabdan kepada Masyarakat Pelatihann Pengembangan Motif Batik berbasis Heritage untuk Perajin Batik di Kawasan Prambanan. Yogyakarta.

UUCB. (2010). Undang-Undang No. 11 tahun 2010 tentang Cagar Budaya. 